\title{
СРАВНИТЕЛЬНАЯ ОЦЕНКА КАЧЕСТВА ВНУТРЕННЕГО ПРИЛЕГАНИЯ ВРЕМЕННЫХ ИСКУССТВЕННЫХ КОРОНОК К КУЛЬТЕ ПРЕПАРИРОВАННОГО ЗУБА, ИЗГОТОВЛЕННЫХ С ПОМОЩЬЮ ТРАДИЦИОННЫХ И ЦИФРОВЫХ ТЕХНОЛОГИЙ
}

\begin{abstract}
COMPARATIVE ASSESSMENT
OF THE QUALITY OF INTERNAL FIT

OF TEMPORARY ARTIFICIAL CROWNS TO THE STUMP OF A PREPARED TOOTH MADE USING TRADITIONAL AND DIGITAL TECHNOLOGIES
\end{abstract}

\section{J. Vokulova \\ E. Zhulev}

Summary. The aim of the study was to study the quality of the internal fit of temporary artificial crowns made using the Asiga Max UV 3D printer, the KaVo ARCTICA CAD/CAM system, using digital images of the experimental model obtained by the intraoral laser scanner iTero Cadent and temporary artificial crowns made by the laboratory method. The size of the internal fit of artificial crowns was measured in the Image J computer program from photos of internal fit silicone replicas made using a Leica M320 operating microscope at 40-fold magnification. The Friedman criterion was used for statistical analysis of the obtained data. It was found that the average value of the cement gap between the tooth stump and the artificial crown made in the KaVo ARCTICA CAD/CAM system is 49,76 $\pm 2,532$ microns, made using the Asiga Max UV 3D printer is 50,00 \pm 1,714 microns, made using the traditional laboratory method without the use of digital technologies, was $151,60 \pm 11,00$ microns. Based on the data obtained, it is concluded that modern digital technologies allow manufacturing temporary artificial crowns with a smaller size of the cement gap, i.e. with significantly higher accuracy in contrast to artificial crowns obtained using traditional technology $(p<0,05)$.

Keywords: digital technologies in dentistry, digital impressions, CAD/CAM, intraoral scanner, 3D printing, internal fit of fixed prostheses.

\section{Введение}

$\mathbf{H}$ еотъемлемой частью протезирования несъемными ортопедическими конструкциями является изготовление временных протезов для защиты подготовленных зубов от воздействия внешних факто-
Вокулова Юлия Андреевна

К.м.н., врач стоматолог - ортопед, ФГКУ «Поликлиника № 2 Федеральной таможенной службы

России», Нижний Новгород

vokulova@rambler.ru

Жулев Евгений Николаевич

Заслуженный работник высшей школы РФ, д.м.н., профессор, ФГБОУ ВО «Приволжский исследовательский медицинский университет» Минздрава России, Нижний

Новгород

hrustalev54@mail.ru

Аннотация. Целью исследования было изучение качества внутреннего прилегания временных искусственных коронок, изготовленных с применением 3D принтера Asiga Max UV, CAD/CAM-системы KaVo ARCTICA, по цифровым изображениям экспериментальной модели, полученным внутриротовым лазерным сканером iTero Cadent и временных искусственных коронок, изготовленных лабораторным методом. Величину внутреннего прилегания искусственных коронок измеряли в компьютерной программе Image J по фотографиям шлифов силиконовых реплик, сделанных с помощью операционного микроскопа Leica M320 под 40-кратным увеличением. Для статистического анализа полученных данных применяли критерий Фридмана. Было выявлено, что среднее значение величины цементного зазора между культей зуба и временной искусственной коронкой, изготовленной в CAD/ CAM системе KaVo ARCTICA составляет 49,76 $\pm 2,532$ мкм, изготовленной с применением 3D принтера Asiga Max UV, составляет 50,00 \pm 1,714 мкM, а изготовленной по традиционному лабораторному методу без использования цифровых технологий, составило 151,60 $\pm 11,00$ мкм. На основании полученных данных сделан вывод о том, что современные цифровые технологии позволяют изготавливать временные искусственные коронки со значительно меньшей величиной цементного зазора, т.е. с существенно большей точностью в отличие от искусственных коронок, полученных с помощью традиционной технологии $(p<0,05)$.

Ключевые слова: цифровые технологии в стоматологии, цифровые оттиски, CAD/CAM, внутриротовой сканер, 3D печать, внутреннее прилегание несъемных протезов.

ров и формирования десневого контура вокруг абатмента имплантата [5]. Известно два метода изготовления временных искусственных коронок - клинический и лабораторный. Среди лабораторных методов можно выделить цифровые и метод с применением горячей полимеризации пластмассы. Из цифровых технологий из- 


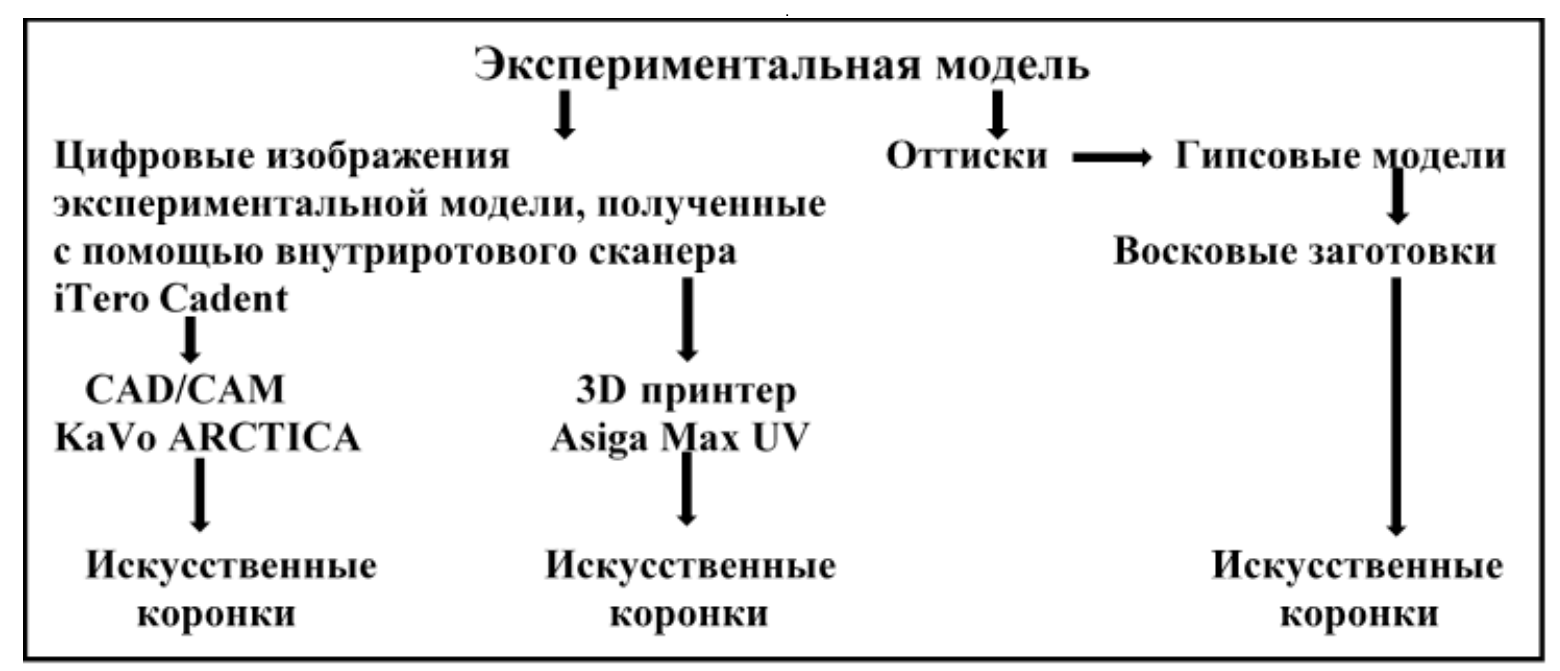

Рис. 1. Схема проведения эксперимента

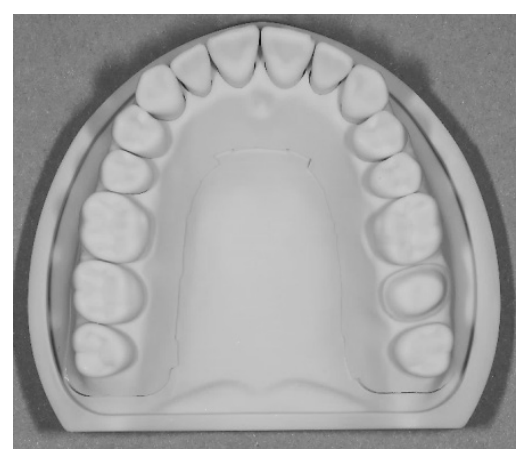

Рис. 2. Экспериментальная модель

готовления временных искусственных коронок на сегодняшний день существует две, основанных на получении изображений зубных рядов с помощью внутриротового либо лабораторного сканера [1, 2, 3, 4] и компьютерного моделирования будущих протезов,- субтрактивный с помощью CAD/CAM-систем $[6,7]$ и аддитивный с помощью 3D принтеров [7]. Основным показателем их качества является плотность прилегания к культе опорного зуба [3]. Однако научных публикаций [8], посвященных изучению качества прилегания временных искусственных коронок к препарированному зубу, изготовленных с помощью традиционных и цифровых технологий, крайне мало, что требует проведения дополнительных исследований в этом направлении.

\section{Цель исслемования}

Изучить качество внутреннего прилегания временных искусственных коронок к культе препарированного зуба, изготовленных с применением 3D принтера Asiga Max UV, CAD/CAM-системы KaVo ARCTICA, по цифровым изображениям экспериментальной модели, получен- ным внутриротовым лазерным сканером iTero Cadent, и искусственных коронок, изготовленных традиционным лабораторным методом.

\section{Материалы и методы исслеАования}

Для изучения внутреннего прилегания временных искусственных коронок, изготовленных с помощью традиционных и цифровых технологий, нами была разработана специальная схема проведения исследования (рис. 1), в которой использовалась экспериментальная модель (рис. 2) с подготовленным под искусственную коронку зубом с циркулярным уступом в виде желоба.

На первом этапе было получено 10 цифровых изображений экспериментальной модели с помощью внутриротового лазерного сканера iTero Cadent (США). В программном обеспечение DentalCAD2.2 Valletta проводили моделирование временных искусственных коронок для культи зуба 2.7 экспериментальной модели. Для всех искусственных коронок при виртуальном моделировании задавали величину цементного зазора 50 мкм. 

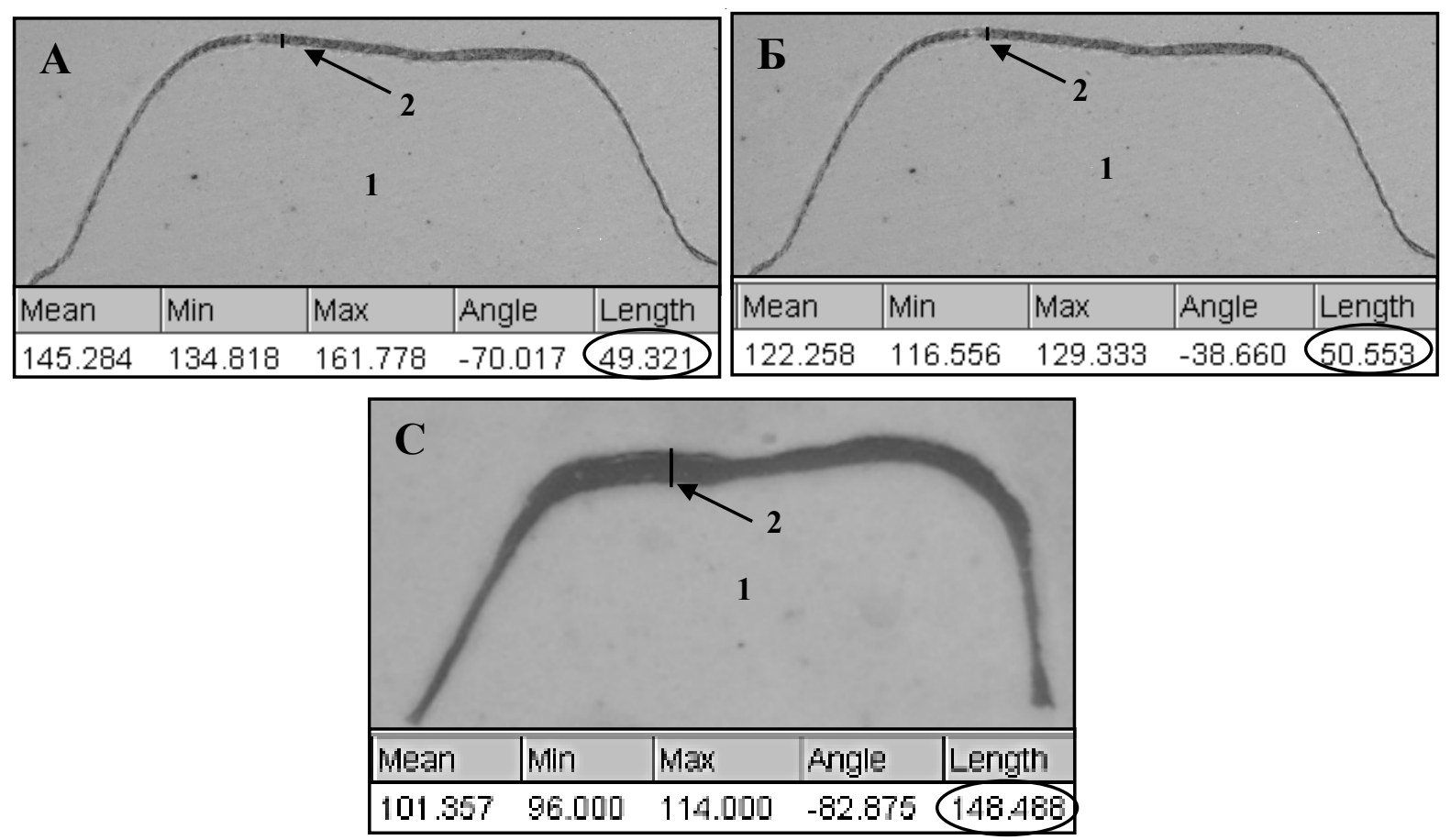

Рис. 3. Измерение величины цементного зазора временных искусственных коронок. 1-гипс, 2 - силиконовая реплика. А. Величина цементного зазора искусственной коронки, изготовленной в CAD/CAM системе KaVo ARCTICA - 49,321 мкм. Б. Величина цементного зазора искусственной коронки, изготовленной с применением 3D принтера Asiga Max UV - 50,553 мкм. С. Величина цементного зазора искусственной коронки, изготовленной по традиционной технологии горячей полимеризации - 148,488 мкм

На втором этапе из полиметилметакрилата VITA CADTemp monocolor в фрезерно-шлифовальном станке KaVo ARCTICA Engine изготовили 10 временных искусственных коронок. На третьем этапе с помощью 3D принтера Asiga Max UV были изготовлены 10 искусственных коронок из биологически совместимого микронаполненного гибридного материала NextDent C\&B MFH.

На третьем этапе с экспериментальной модели были получены двухслойные одноэтапные А силиконовые оттиски (Express STD, Express XT Regular Body, 3M ESPE, США) и изготовлены 10 разборных моделей из высокопрочного гипса Fujirock (GC, Япония). Создавали восковые заготовки искусственных коронок, методом погружения до получения необходимой толщины. Моделировали литники, формовали в опоку, выплавляли воск и методом с применением горячей полимеризации изготавливали 10 временных искусственных коронок из акриловой пластмассы СинмаМ.

Для оценки внутреннего прилегания полученных искусственных коронок была использована следующая методика. Искусственные коронки заполняли корригирующим оттискным материалом Speedex light body, Coltene (Швейцария) и фиксировали на культю экспери- ментальной модели. По истечении времени, необходимого для полимеризации корригирующего оттискного материала, коронки снимали с культи и извлекали силиконовый оттиск, отображающий качество внутреннего прилегания искусственных коронок. Далее силиконовую реплику гипсовали. Для каждой искусственной коронки получали два оттиска внутреннего прилегания. Одну реплику разрезали в мезио-дистальном, другуюв вестибуло-оральном направлении, получая тем самым 4 шлифа, отображающих внутреннее прилегание искусственной коронки. Затем с помощью операционного микроскопа Leica M320 под 40-кратным увеличением получали фотографии шлифов. В компьютерной программе Image J проводили измерения величины силиконовой реплики, отражающей плотность внутреннего прилегания искусственных коронок (рис. 3). На каждом шлифе проводили 10 измерений. Результаты измерений заносили в таблицы для последующего статистического анализа.

При оценке внутреннего прилегания полученных искусственных коронок особое внимание уделяли величине цементного зазора, равномерности распределения корригирующего материала на поверхности культи, расположению края коронки на уступе культи 2.7 экспери- 
Таблица 1. Средние величины цементного зазора искусственных коронок, изловленных разными методами, мкм ( $\mathrm{n}$ - количество искусственных коронок)

\begin{tabular}{|l|l|l|l|}
\multirow{2}{*}{$\mathbf{n}$} & \multicolumn{4}{|l|}{ Метод изготовления каркасов искусственных коронок } \\
\cline { 2 - 4 } & KaVo ARCTICA & 3D принтер ASIGA & Традиционный лабораторный метод \\
\hline 1 & 48,60 & 49,91 & 154,67 \\
\hline 2 & 52,12 & 49,91 & 157,93 \\
\hline 3 & 46,38 & 51,55 & 146,27 \\
\hline 4 & 47,87 & 48,93 & 155,47 \\
\hline 5 & 46,76 & 47,93 & 124,14 \\
\hline 6 & 50,46 & 51,12 & 153,28 \\
\hline 7 & 47,87 & 46,73 & 151,73 \\
\hline 8 & 52,07 & 50,36 & 165,04 \\
\hline 9 & 52,72 & 52,34 & 158,79 \\
\hline 10 & 52,70 & 50,10 & 148,85 \\
\hline Среднее значение & 49,76 & 49,89 & 151,62 \\
\hline
\end{tabular}

Таблица 2. Описательные статистики распределения значений величины цементного зазора ( $\mathrm{n}$ количество каркасов искусственных коронок)

\begin{tabular}{|l|l|l|l|l|l|l|l|l|}
$\begin{array}{l}\text { Метод получения } \\
\text { коронок }\end{array}$ & $\mathbf{n}$ & $\begin{array}{l}\text { Среднее } \pm \\
\text { стандартное } \\
\text { отклонение }\end{array}$ & Медиана & Минимум & Максимум & $\begin{array}{l}\text { 25-й про- } \\
\text { центиль }\end{array}$ & $\begin{array}{l}\text { 75-й про- } \\
\text { центиль }\end{array}$ & $\begin{array}{l}\text { Стандартная } \\
\text { ошибка } \\
\text { среднего }\end{array}$ \\
\hline САD/САМ & 10 & $49,76 \pm 2,532$ & 49,53 & 46,38 & 52,72 & 47,87 & 52,11 & 0,80 \\
\hline 3D принтер & 10 & $50,00 \pm 1,714$ & 50,23 & 46,73 & 52,34 & 49,17 & 51,09 & 0,54 \\
\hline $\begin{array}{l}\text { Традиционная } \\
\text { техника }\end{array}$ & 10 & $151,60 \pm 11,00$ & 154,00 & 124,10 & 165,00 & 149,6 & 157,30 & 3,48 \\
\hline
\end{tabular}

Таблица 3. Результаты попарного сравнения групп

\begin{tabular}{|l|l|}
\hline Сравниваемые группы & $\mathbf{p}$ \\
\hline CAD/CAM - 3D принтер & 1,00000000000 \\
\hline Традиционная техника - 3D принтер & 0,00000001312 \\
\hline Традиционная техника - CAD/CAM & 0,00000001312 \\
\hline
\end{tabular}

ментальной модели и необходимости припасовки искусственной коронки к культе зуба.

\section{Результаты \\ исслеАОвания \\ и их обсу жАение}

Результаты по измерению величины цементного зазора искусственных коронок представлены в таблице 1.

Для анализа полученных результатов применяли критерий Фридмана. Критерий Фридмана позволяет установить, что величины показателей изменяются от условия к условию, но при этом не указывает на направление изменений. Критерий Фридмана является обобщением критерия Уилкоксона на большее чем два количество условий измерения, в котором мы ранжируем не абсолютные величины сдвигов, а сами индивидуальные зна- чения измерений. Нулевую гипотезу при статистическом анализе обозначили следующим образом $\mathrm{H} 0=\{$ между полученными в разных условиях показателями существуют лишь случайные различия\}.

В данном исследовании нулевая гипотеза отвергается на уровне статистической значимости $p<0,0166667$, т.е. вероятность ошибочного признания различий значимыми меньше 0,0166667. При расчете критического уровня значимости была введена поправка Бонферрони для учета множественных сравнений: 0,0166667 = 0,05 / 3, где 0,05 - общепринятое значение критического уровня значимости для одинарного сравнения в медико-биологических исследованиях, а 3 - число сравнений.

Описательные статистики распределения значений величины цементного зазора представлены в таблице 2. 
A

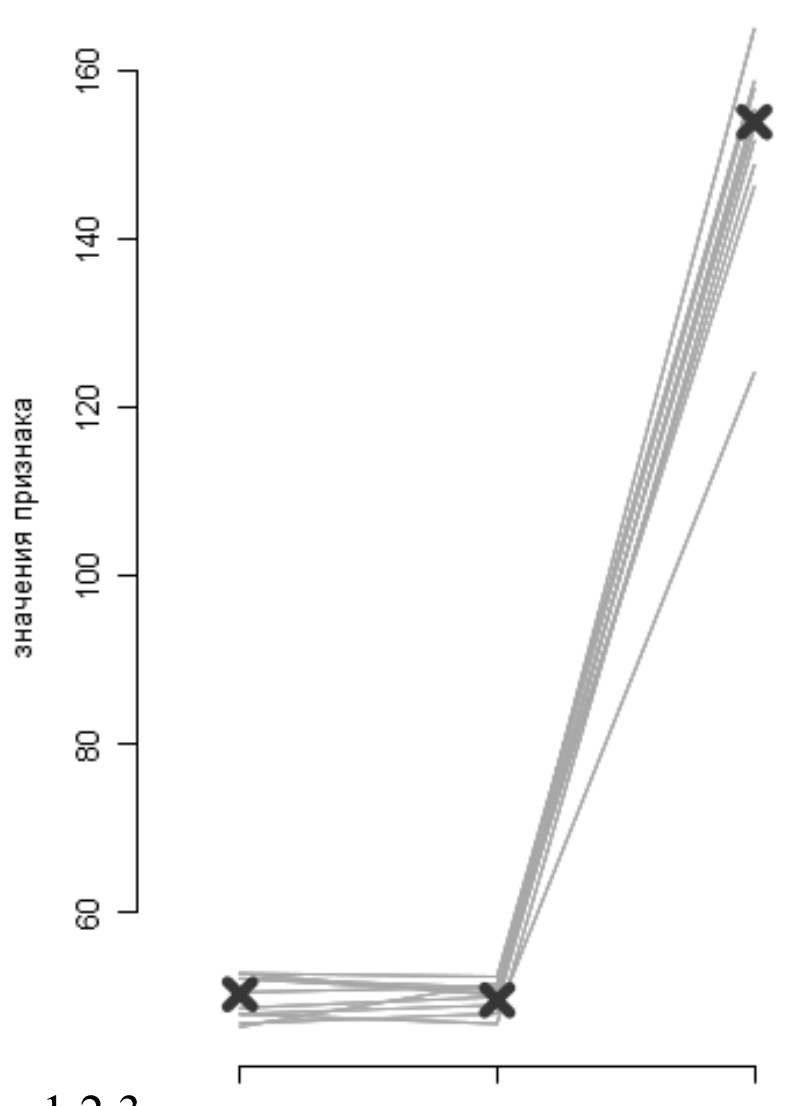

123

Параллельные координаты
Б Коробчатый график (для разниц)

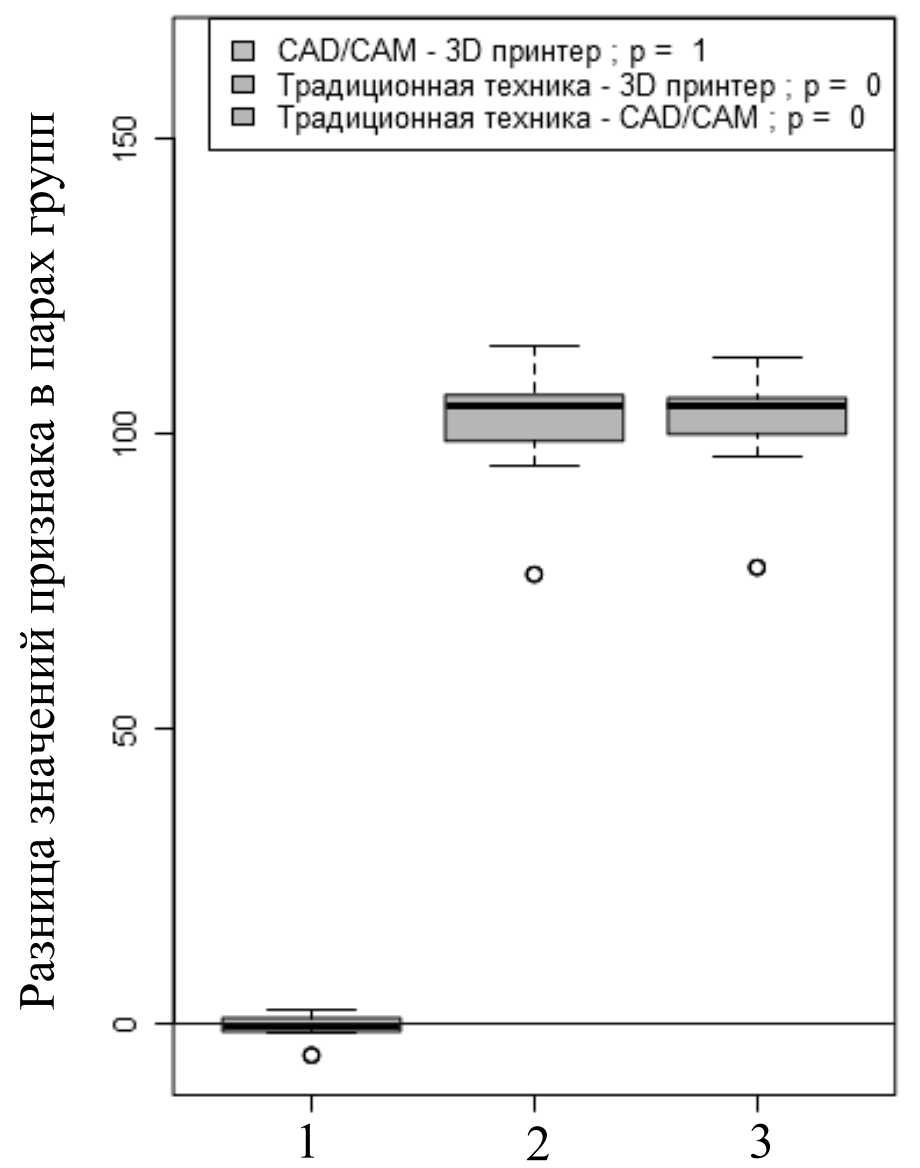

Рис. 4. Анализ различий значений признака «Цементный зазор» А. Диаграмма с параллельными координатами. Б. Коробчатый график для попарно сравниваемых групп: 1 - CAD/CAM - 3D принтер; 2 - Традиционная техника - CAD/CAM; 3 - Традиционная техника - 3D принтер

Различия величин цементного зазора временных искусственных коронок, изготовленных различными методами, можно признать статистическими значимыми на уровне $\mathrm{p}<0,0166667$ (критерий Фридмана S $=45,000000, \mathrm{p}=0,000000)$. Далее проводили попарное сравнение всех цифровых методик, применяемых для изготовления временных искусственных коронок, с традиционным методом горячей полимеризации пластмассы и цифровых методик между собой (табл. 3, рис. 4).

Из таблицы 3 и рисунка 4 видно, что цифровые методики изготовления временных искусственных коронок различимы от традиционного метода горячей полимеризации с уровнем значимости $\mathrm{p}<0,0166667$ по признаку «Величина цементного зазора». Статистических различий между методами изготовления искусственных коронок с помощью CAD/CAM системы и 3D принтера не обнаружено.
Нами было выявлено, что среднее значение величины цементного зазора между культей зуба и временной искусственной коронкой, изготовленной в CAD/CAM системе KaVo ARCTICA составляет 49,76 \pm 2,532 мкм. Среднее значение величины цементного зазора между культей зуба и временной искусственной коронкой, изготовленной с применением 3D принтера Asiga Max UV, составляет 50,00 \pm 1,714 мкм. Среднее значение величины цементного зазора между культей зуба и временной искусственной коронкой, изготовленной по традиционному лабораторному методу без применения цифровых технологий, составляет 151,60 \pm 11,00 мкм. В ходе исследования мы пришли к выводу, что величины цементного зазора временных искусственных коронок, изготовленных с помощью современных цифровых технологий (внутриротовое лазерное сканирование, CAD/CAM-система, 3D принтер) и по традиционному лабораторному методу, статистически различимы с уровнем значимости $\mathrm{p}<0,0166667$. 
Таблица 4. Результаты изучения внутреннего прилегания искусственных коронок

\begin{tabular}{|l|l|l|l|}
\hline $\begin{array}{l}\text { Метод изготовления } \\
\text { искусственных коронок }\end{array}$ & $\begin{array}{l}\text { Величина } \\
\text { цементного зазора, } \\
\text { мкм }\end{array}$ & Необходимость припасовки & $\begin{array}{l}\text { Равномерность пленки корригирующего } \\
\text { слоя на всей поверхности культи }\end{array}$ \\
\hline CAD/CAM KaVo ARCTICA & $49,76 \pm 2,532$ & Hе нужно & Равномерно \\
\hline 3D принтер Asiga & $50,00 \pm 1,714$ & Не нужно & Равномерно \\
\hline Лабораторный метод & $151,60 \pm 11,00$ & 30\% нуждались в припасовке & Неравномерно \\
\hline
\end{tabular}

Bсе временные искусственные коронки, изготовленные с применением CAD/CAM-системы KaVo ARCTICA и 3D принтера Asiga Max UV, не нуждались в припасовке. Края искусственных коронок плотно прилегали к уступу культи 2.7 экспериментальной модели, зонд не застревал на стыке коронки и культи в области придесневого уступа. Корригирующий материал равномерно распределялся на поверхности культи 2.7 при получении силиконовой реплики внутреннего прилегания искусственных коронок.

Края временных искусственных коронок, изготовленных по традиционному лабораторному методу, ощущаются при зондировании зоны придесневого уступа. Три искусственных коронки (30\%), изготовленных без применения цифровых технологий, нуждались в дополнительной припасовке. Корригирующий материал неравномерно распределялся на поверхности культи 2.7 при получении силиконовой реплики внутреннего прилегания искусственных коронок. Результаты изучения качества внутреннего прилегания искусственных коронок представлены в таблице 4.

В этом плане представляют интерес исследования иностранных авторов, занимающихся изучением данной проблемы. В частности, W.S. Lee с соавт. [8] в своем исследовании выявили статистически значимые различия в величине цементного зазора временных искусственных коронок, изготовленных с помощью CAD/CAM-системы Zirkonzahn и двух 3D принтеров Stratasys и Dentis. Средняя величина цементного зазора, временных искусственных коронок, изготовленных с применением CAD/CAM системы Zirkonzahn, по данным этих авторов, составила 266,3 \pm 36,0 мкм. Средняя величина цементного зазора, временных искусственных коронок, изготовленных с применением 3D принтера Stratasys составила $172,4 \pm 43,3$ мкм. Средняя величина цементного зазора, временных искусственных коронок, изготовленных с применением 3D принтера Dentis составила 107,5 \pm 34,5 мкм. На наш взгляд, различия в полученных результатах, объясняются прежде всего тем, что применялись разные CAD/CAM-системы и 3D принтеры. Мы использовали для получения цифрового изображения экспериментальной модели внутриротовой сканер в отличии от зарубежных авторов, которые сканировали гипсовую рабочую модель лабораторным сканером, что и приводит к увеличению величины цементного зазора временных искусственных коронок.

\section{Зак^ючение}

Современные цифровые технологии, применяемые в ортопедической стоматологии (внутриротовое лазерное сканирование с помощью сканера iTero Cadent, CAD/CAM-система KaVo ARCTICA, 3D принтер Asiga Max UV) позволяют изготавливать временные искусственные коронки с меньшей величиной цементного зазора и лучшем качеством внутреннего прилегания в отличие от искусственных коронок, полученных с помощью традиционного лабораторного метода с применением горячей полимеризации пластмассы с уровнем значимости $\mathrm{p}<0,05$ (критерий Фридмана $\mathrm{S}=45,000000, \mathrm{p}=$ 0,000000). Статистических различий по признаку «величина цементного зазора» для временных искусственных коронок, изготовленных с помощью CAD/CAM системы и 3D принтера мы не обнаружили.

\section{ЛИТЕРАТУРА}

1. Вокулова Ю. А. Разработка и внедрение цифровых технологий при ортопедическом лечении с применением несъемных протезов зубов: Автореф. дис. ... кандидата медицинских наук (14.01.14). Нижний Новгород, 2017. 22 с.

2. Вокулова Ю.А., Жулев Е. Н. Оценка точности получения оттисков зубных рядов с применением технологии лазерного сканирования // Современные проблемы науки и образования.— 2016. — № 5; URL: http://www.science-education.ru/ru/article/view?id=25447. 
3. Жулев Е.Н., Вокулова Ю. А. Изучение размерной точности внутреннего прилегания искусственных коронок к культе опорного зуба и цифровых оттисков в эксперименте // Кубанский научный медицинский вестник. - 2016. — № 6 (161). — c. 58-62.

4. Жулев Е.Н., Вокулова Ю. А. Изучение размерной точности цифровых оттисков, полученных с помощью внутриротового сканера iТеrо // Международный журнал прикладных и фундаментальных исследований. — 2016. — № 12-2. — C. 257-261. URL: https://applied-research.ru/ru/article/view?id=10818

5. Розенштиль С. Ф. Ортопедическое лечение несъемными протезами. М.: Медпресс, 2010. 940 с.

6. Ряховский, А. Н. Цифровая стоматология. М.: 000 «Авантис», 2010. 282 с.

7. Шустова В.А., Шустов М. А. Применение 3D-технологий в ортопедической стоматологии. СПб: СпецЛит, 2016. 159 с.

8. Lee W.S., Lee D. H., Lee K. B. Evaluation of internal fit of interim crown fabricated with CAD/CAM milling and 3D printing system // J Adv Prosthodont. 2017. N9. P. 265-270. D0I:10.4047/jap.2017.9.4.265.

(c) Вокулова Юлия Андреевна ( vokulova@rambler.ru ), Жулев Евгений Николаевич ( hrustalev54@mail.ru ).

Журнал «Современная наука: актуальные проблемы теории и практики»

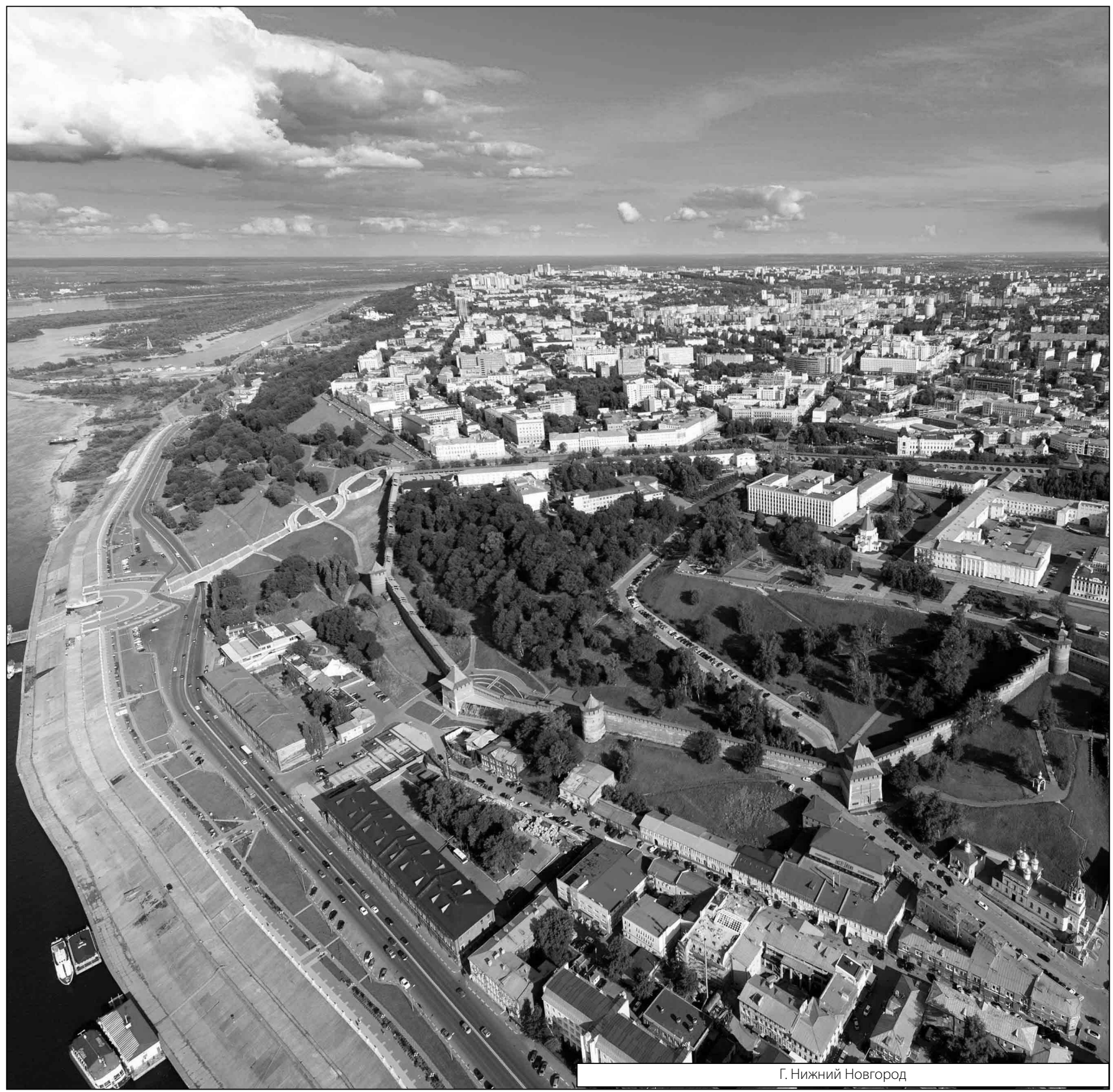

